\title{
IRISIN: A POTENTIAL PROMISING AGENT AGAINST NON-ALCOHOLIC FATTY LIVER DISEASE IN TYPE 2 DIABETIC RATS
}

\author{
By \\ Hany A. El-Kattawy a, b,c and Wesam M. R. Ashour ${ }^{\text {a }}$ \\ Physiology Department ${ }^{\mathrm{a}}$, Zagazig Obesity Management \& Research Unit ${ }^{\mathrm{b}}$ Faculty of \\ Medicine; Zagazig University; Egypt and College of Medicine ${ }^{c}$; Al maarefa University; \\ Saudi Arabia
}

\begin{abstract}
Background: Non-alcoholic fatty liver disease (NAFLD) is strongly related to obesity, insulin resistance and type 2 diabetes. Irisin is an exercise-induced myokine which improves glucose profile and insulin resistance.

Objective: To evaluate the potential effects of irisin on liver function in type 2 diabetic rats with NAFLD and elucidate the underlying mechanisms.

Material and methods: Thirty adult male albino rats were divided into 3equal groups: control rats, type 2 diabetic with NAFLD rats, and type II diabetic rats with NAFLD received irisin $(0.5$ ? g/g body weight once daily for 8 weeks). Diabetes was induced by high fat diet for 12 weeks followed by injection of small dose of streptozotocin $(35 \mathrm{mg} / \mathrm{kg}$ body weight). Eight weeks after establishment of diabetes, body mass index and abdominal circumference were estimated. Serum was analysed for glucolipid metabolic parameters, liver enzymes, C-reactive protein, tumour necrosis facror- $\alpha$. Liver homogenate was assayed for malondialdehyde, superoxide dismutase, and glutathione s-transferase activities. Liver sections were stained with Hematoxlyin $\&$ eosin.
\end{abstract}

Results: Irisin treatment significantly improved glucolipid metabolic parameters, liver enzymes, antioxidante enzymes accompanied by significant decrease in inflammatory mediators and malondialdehyde levels, with improvement of the histopathological findings.

Conclusion: Irisin may be used as a promising agent against NAFLD in type 2 diabetic rats possibly through controlling glucose and lipid metabolism and via its beneficial anti-inflammatory and anti-oxidant effects as well.

Keywords: Irisin, Type 2 Diabetes, Fatty Liver, High- Fat Diet, Rats.

\section{INTRODUCTION}

Non-alcoholic fatty liver disease (NAFLD) is the most common form of chronic liver disease and is characterized by diffused steatosis and hepatocyte lipid accumulation without substantial alcohol intake. NAFLD may progress to nonalcoholic steatohepatitis (NASH), leading to liver fibrosis and hence cirrhosis (Sanyal et al., 2011and El-Sherbiny et al., 2018). Further, it is associated with hyperlipidemia, obesity and type II diabetes (Higuera de la Tijera and Serv?n Caama?o, 2015). Moreover, it is associated with a high mortality rate due to an increased risk of cardiovascular disease and hepatoma (Hassan et al., 2014). The complexity of NAFLD pathogenesis is multifactorial and explained by the "multiple hit theory", where many factors, such as genetic predisposition, insulin resistance, altered 
adipokine production, endoplasmic reticulum stress and mitochondrial dysfunction, are involved. These factors could also explain the various disease patterns among NAFLD patients (Buzzetti et al., 2016).

In the early stages of NAFLD, the disease can be managed by lifestyle changes in the form of weight reduction and exercise (Arias-Loste et al., 2014). However, the advanced conditions are treated by adding insulin sensitizers, lipid lowering agents and antioxidants as well (Fruci et al., 2013; Del Ben et al., 2014 and Leite et al., 2014). Unfortunately, these drugs have potential long-term side effects. Therefore, there is a considerable demand to develop effective and safe therapies for the management of NAFLD (Issa et al., 2018).

Irisin, is a 112 amino acid myokine as a cleaved form of fibronectin type III domain-containing protein 5 (FNDC5) (Bostr?m et al., 2012), this myokine secreted chiefly in skeletal and cardiac muscles. However, little is detected in adipose tissue and liver (Aydin et al., 2014). Physiologically, irisin release from skeletal muscles is increased following exercise and ATP depletion (L?ffler et al., 2015; Palacios-Gonz?lez et al., 2015 and Panati et al., 2016). Hence, it can induce browning of white adipose tissue, increasing heat production and energy expenditure (Virtanen, 2014).

Irisin was found to stimulate glucose uptake by skeletal muscles, improving liver glucose and lipid metabolism and leading to the relief of hyperglycemia, insulin resistance and hyperlipidemia in obesity-related conditions (Chen et al., 2016 and So \& Leung, 2016).
This study aimed to evaluate the potential effects of irisin on liver function in type 2 diabetic rats with NAFLD and elucidate the underlying mechanisms.

\section{MATERIALS AND METHODS}

- Animals: Thirty healthy adult male Wistar albino rats weighing 180-210 g were obtained from the Faculty of Veterinary Medicine, Zagazig University. The animals were kept under hygienic conditions in steel wire cages $(40 \mathrm{~cm} 28 \mathrm{~cm} 18 \mathrm{~cm}-5 \mathrm{rats} /$ cage) in the animal facility of the Physiology Department, Faculty of Medicine, Zagazig University. Animals had free access to water and were maintained at room temperature on a 12 - hour light/dark cycle. The rats were acclimatized to the animal facility conditions for one week before the experiments. The experimental protocols were approved by the Zagazig University Institutional Animal Care Unit Committee (ZUIACUC; Sharqia, Egypt).

This study was performed from August, 2018 to February, 2019. After acclimation for one week, the rats were randomly assigned to three equal groups.

In Group I (normal controls), the rats were fed a standard normal chow diet consisting of $25.8 \%$ protein, $62.8 \%$ carbohydrates and $11.4 \%$ fat (as a percentage of total $\mathrm{kcal}$ ) for 12 weeks (Ahrén and Scheurink, 1998). In Group II (type II diabetic rats with NAFLD), a type 2 diabetes model was established by feeding animals a high-fat diet (HFD) consisting of $58.8 \%$ fat, $26 \%$ carbohydrates and $15.2 \%$ protein (as a percentage of total $\mathrm{kcal}$ ) (The diets were obtained from The Agriculture Faculty, 
Zagazig University. After twelve weeks of dietary manipulation, all rats were fasted for 12 hours with free access to water. Then, the rats received an intraperitoneal injection of low dose streptozotocin (STZ) (35 $\mathrm{mg} / \mathrm{kg}$ body weight) (Sigma Chemical, St. Louis, MO, Sigma-Aldrich, U.S.A). However, the control rats fed a standard normal chow diet were given an equivalent volume of saline. Blood glucose was checked seven days after STZ injection. Animals with blood glucose levels $\geq 250 \mathrm{mg} / \mathrm{dl}$ were chosen for the study (Hu et al., 2013). This group was maintained for eight weeks after induction of diabetes with NAFLD. In Group III (type II diabetic rats with NAFLD received irisin), diabetic rats received intraperitoneal injections of irisin (Phoenix Pharmaceuticals, Inc. Burlingame, USA) at a dose of 0.5 ?g/g body weight once daily for 8 weeks (Zhang et al., 2014a and Xin et al., 2015). The control and untreated diabetic groups (I and II) received intraperitoneal injections of phosphate buffered solution (PBS) at the same dose and duration as irisin (Xin et al., 2015).

\section{Measurement of anthropometric parameters:}

- Body mass index (BMI) (g/cm2) was calculated by dividing body weight (gm) by length $2(\mathrm{~cm} 2)$. The obesity cut-off value was a BMI above $0.68 \mathrm{~g} / \mathrm{cm} 2$ (Novelli et al., 2007).

- Abdominal circumference (AC), rats were placed in the ventral position, and the abdominal circumference was assessed in the largest zone of the rat's abdomen using a plastic non-extensible measuring tape (Gerbaix et al., 2010).
Blood sampling and biochemical analysis: Blood samples were obtained from the retro-orbital venous plexus at the end of the experimental period between 911 A.M. after overnight fasting (Yang et al., 2006 and Lemos et al., 2011). The blood was collected in plastic centrifuge tubes and allowed to clot. Serum was separated by centrifugation at $3000 \mathrm{rpm}$ for 15 minutes. The supernatant serum was pipetted off and stored frozen at -20 ?C (Nishizawa et al., 2002) until assayed for assessment of the following:

1. Serum glucose, insulin levels and insulin resistance

- Serum glucose levels (mg/dl) were measured as described by Tietz (1995), and serum insulin levels (? IU/ml) were measured by enzyme linked immunosorbent assay (ELISA) according to Reaven (1991). Kits for serum glucose and insulin levels were purchased from Biosource Europe S.A. Belgium.

- Homeostasis model assessment-insulin (HOMA-IR) was calculated using the HOMA-IR index according to the equation used by Bonora et al. (2000): HOMA-IR = fasting serum glucose $(\mathrm{mg} / \mathrm{dL}) \times$ fasting serum insulin $(? \mathrm{IU} / \mathrm{mL}) / 405$.

\section{Lipid profile}

- Serum total cholesterol (TC) and triglycerides (TG) levels were measured by an enzymatic colorimetric method using specific cholesterol and triglycerides kits (Spinreact Spain), and analysed by a spectrophotometer as described in previous studies (Fossati and \& Prencipe, 1982 and Tietz, 1995). HDL-c levels were measured as described by Nauck et al. (1997). 
Serum LDL-c levels were calculated by using the Friedewald formula (Friedewald et al., 1972) as follows: $\mathrm{LDL}-\mathrm{c}=\mathrm{TC}-\mathrm{HDL}-\mathrm{TG} / 5$.

\section{Liver enzyme assays}

- Serum alanine aminotransferase (ALT) and aspartate aminotrans-ferase (AST) levels were measured via a Rat ALT ELISA kit (Kamiya Biomedical Company, KT-6104, Gateway Drive, Seattle) and a Rat AST ELISA kit (Sunred Biological Technology, China), respectively, according to the method of Vassault (1983).

\section{Serum albumin}

- Serum albumin was estimated by using bromocresol green according to the method described by Stoskopf (1993).

\section{Serum irisin level}

- Serum irisin was measured as described by Bostr?m et al. (2012) using an irisin ELISA rat kit (Catalogue \# K4761-100, BioVision, Milpitas Blvd., Milpitas, CA 95035 USA).

\section{Inflammatory markers}

- TNF- $\alpha$ concentration was measured by ELISA as described by Fernando et al. (1998) using commercial kits purchased from ALPCO (45-TNFRTE01.1). Absorbance was measured at $450 \mathrm{~nm}$.

- C-reactive protein (CRP) was estimated by kits (Monobind Inc., Lake Forest, Ca 92630, USA) as described by Kimberly et al. (2003).

\section{Assessment of oxidative stress markers in liver homogenate:}

Liver tissues were processed to obtain $10 \%(\mathrm{w} / \mathrm{v})$ homogenate in ice-cold $20 \mathrm{mM}$ tris (hydroxymethyl) amino-methane buffer ( $\mathrm{pH}$ 7.4). Homogenates were centrifuged at $3000 \times \mathrm{g}$ for 30 minutes at $4{ }^{\circ} \mathrm{C}$. The supernatants were collected and assayed as follows:

- Hepatic malondialdehyde (MDA), a lipid peroxidation indicator, was estimated using a Bio diagnostic kit according to Varshney and Kale (1990).

- Hepatic superoxide dismutase (SOD) was determined using phenazine metho sulfate (PMS) depending on the SOD ability to inhibit the PMS-mediated reaction of nitro-blue tetrazolium as described by Misra and Fridovich (1972).

- Glutathione S-transferase (GST) activity was assayed using 1-chloro-2, 4dinitrochlorobenzene as a substrate according to (Rajurkar et al., 2003). A GST unit is defined as $1 \mathrm{~mol}$ of CDNB$\mathrm{GSH}$ conjugate formed/min/mg protein.

\section{Liver extraction and histopatholo-gical examination:}

After blood sample collection, the rats were sacrificed by cervical dislocation under mild isoflurane anesthesia, and then laparotomy was conducted. The livers were quickly removed, cleaned and processed for histopathological examinations. The excised livers were fixed in $10 \%$ buffered formalin solution for 48-60 hours. Then, tissue samples were processed through an ethyl alcohol and xylene series and embedded in paraffin blocks. Liver specimens were sectioned ( $5 \mu \mathrm{m}$ thick) and then stained with hematoxylin and eosin (Altunkaynak, 2005). A pathologist evaluated and scored the stained samples in a blind fashion 
using a light microscope with camera attachment. The histological scoring of NAFLD followed the NAFLD Activity Score (NAS) proposed by The Pathological Committee of the NASH Clinical Research Network (Kleiner et al., 2005). The scores are as follows: steatosis $(0=<5 \%, 1=5 \%-33 \%, 2=34 \%-66 \%$, $3=>66 \%)$, lobular inflammation $(0=$ no foci, $1=<2$ foci per $200 \times$ field, $2=2-4$ foci per $200 \times$ field, $3=>4$ foci per $200 \times$ field), and ballooning ( $0=$ none, $1=$ rare or few, 2 =many or prominent). Fibrosis staging was recorded as the following criteria: $0=$ none, $1=$ perisinusoidal or periportal fibrosis, $2=$ perisinusoidal and portal/periportal fibrosis, $3=$ bridging fibrosis and $4=$ cirrhosis. A NAS score $\geq$ 5 was defined as NASH; $2<\mathrm{NAS}<5$ was defined as borderline NASH; and NAS $\leq$ 2 was simple steatosis (Zhao et al., 2004). Cirrhosis was defined as grade 4 fibrosis plus other features of the NAS score.

\section{Immunohistochemical staining with anti-caspase-3 antibody:}

Liver slides were stained with rabbit anti-Caspase-3 antibody (cat\# ab4051, Abcam, USA) to identify apoptotic areas.
The deparaffinized sections were bathed in phosphate-buffered saline, and endogenous peroxidase activity was obstructed by incubation with $3 \%$ hydrogen peroxide for 10 minutes at room temperature. Then, sections were incubated with a primary antibody overnight to detect the presence of apoptosis markers. Liver sections were counterstained with hematoxylin (ElSherbiny et al., 2018).

According to the intensity of the staining, caspase 3 expression was scored into 3 grades: $1+$ weak or negative, $2+$ moderate, and $3+$ strong (Dozic et al., 2016).

\section{Statistical analysis:}

Statistical analysis was performed by using SPSS 19 (SPSS Inc. Chicago, IL, USA). ANOVA with Post hoc (LSD) was used to compare means among the groups. The correlations between parameters were analyzed using Pearsons correlation. $\mathrm{P}$ value $<0.05$ was considered indicative of statistical significance.

\section{RESULTS}

In group II (Type II diabetic rats with NAFLD), there was a significant increase in final body weight, liver weight, liver/ body weight ratio, AC , final BMI, serum glucose, insulin, HOMA-IR, cholesterol, triglycerides, LDL, ALT, AST, TNF- $\alpha$, CRP and hepatic MDA $(\mathbf{P}<\mathbf{0 . 0 0 1})$ in comparison to group I (control). However, there was a significant decrease in serum irisin, HDL, albumin, hepatic SOD and hepatic GST $(\mathrm{P}<0.001)$ in the same group [Tables 1, 2, 3].
In group III (Type II diabetic rats with NAFLD received irisin), irisin administration resulted in a significant decrease in final body weight, liver weight, liver/ body weight ratio $(\mathrm{P}<$ 0.01), AC $(\mathrm{P}<0.05)$, final $\mathrm{BMI}$, serum glucose, insulin, HOMA-IR $(\mathrm{P}<0.001)$, cholesterol, triglycerides, LDL ( $\mathrm{P}<0.01)$, ALT, AST (P < 0.001), TNF- $\alpha$, CRP $(\mathrm{P}<$ $0.01)$ and hepatic MDA ( $\mathrm{P}<0.001)$, but significantly increased serum HDL ( $\mathrm{P}<$ 0.01), irisin, albumin, hepatic SOD, and hepatic GST $(\mathrm{P}<0.001)$ in comparison to 
group II (Type II diabetic rats with NAFLD) [Tables 1, 2, 3].

Furthermore, There was significant negative correlation between irisin levels and each of final BMI, AC, serum glucose, insulin, HOMA-IR, cholesterol, triglycerides, LDL, HDL, albumin, ALT,
AST, TNF- $\alpha$, CRP and hepatic MDA in all studied groups. However, was significant positive correlation between irisin levels and each of hepatic SOD and hepatic GST in all studied groups [Tables $1,2,3]$.

Table (1): Anthropometric parameters in all studied groups

\begin{tabular}{|c|c|c|c|c|}
\hline Parameters & Groups & $\begin{array}{l}\text { Group I } \\
\text { (control) }\end{array}$ & $\begin{array}{c}\text { Group II } \\
\text { (Type II diabetic } \\
\text { rats with } \\
\text { NAFLD) } \\
\end{array}$ & $\begin{array}{c}\text { Group III } \\
\text { (Type II diabetic rats } \\
\text { with NAFLD } \\
\text { received irisin) } \\
\end{array}$ \\
\hline Final body weight (gm) & $\overline{\mathrm{X}} \pm \mathbf{S D}$ & $196.62 \pm 13.2$ & $281.50 \pm 13.9^{* * * *}$ & $247.62 \pm 21.3^{\dagger * * * * * *}$ \\
\hline Liver weight (gm) & $\overline{\mathrm{X}} \pm \mathbf{S D}$ & $8.32 \pm 0.6$ & $13.80 \pm 0.8^{\ddagger * * *}$ & $12.35 \pm 0.7^{\text {****\&** }}$ \\
\hline $\begin{array}{l}\text { Liver/ body weight ratio } \\
(100 \%)\end{array}$ & $\overline{\mathrm{X}} \pm \mathbf{S D}$ & $4.25 \pm 0.1$ & $5.01 \pm 0.1^{\text {f*** }^{* *}}$ & $4.8 \pm 0.1^{* * * * \S^{* * *}}$ \\
\hline Final BMI (gm/cm2) & $\begin{array}{l} \pm \underset{(\mathbf{S D})}{\mathrm{S}} \overline{\mathrm{X}} \\
\end{array}$ & $\begin{array}{l}0.58 \pm 0.04 \\
(-0.819 *)\end{array}$ & $\begin{array}{c}0.88 \pm 0.07^{\text {t**** }} \\
\left(-0.832^{*}\right)\end{array}$ & $\begin{array}{c}0.68 \pm 0.04^{* * * \beta^{* * * *}} \\
\left(-0.771^{*}\right)\end{array}$ \\
\hline $\mathrm{AC}(\mathrm{cm})$ & $\underset{(\mathbf{r})}{ \pm \operatorname{SD} \bar{X}}$ & $\begin{array}{c}17.50 \pm 1.9 \\
\left(-0.726^{*}\right)\end{array}$ & $\begin{array}{l}22.00 \pm 2.00^{* * * *} \\
\quad\left(-0.835^{* *}\right)\end{array}$ & $\begin{array}{l}19.79 \pm 2.1^{* * 8^{*}} \\
\left(-0.741^{*}\right)\end{array}$ \\
\hline
\end{tabular}

$\$=$ vs group I; $\S=$ vs group II; $\mathbf{r}=$ correlation coefficient versus irisin level; $*=$ significant $(\mathbf{P}<0.05)$;

$* *=$ significant $(\mathbf{P}<0.01) ; * * *=$ significant $(\mathbf{P}<0.001)$. 
IRISIN: A POTENTIAL PROMISING HEPATOPROTECTIVE AGENT...

Table (2): Serum biochemical parameters in all studied groups

\begin{tabular}{|c|c|c|c|c|}
\hline \multicolumn{2}{|c|}{$\begin{array}{ll}\text { Parameters } & \text { Groups } \\
\end{array}$} & \multirow{2}{*}{$\begin{array}{l}\begin{array}{l}\text { Group I } \\
\text { (control) }\end{array} \\
\mathbf{8 2 . 3 7} \pm \mathbf{7 . 4} \\
\end{array}$} & \multirow{2}{*}{$\begin{array}{c}\text { Group II } \\
\begin{array}{c}\text { (Type II diabetic rats } \\
\text { with NAFLD) }\end{array} \\
\mathbf{2 7 0} \pm \mathbf{2 0}\end{array}$} & \multirow{2}{*}{$\begin{array}{c}\text { Group III } \\
\text { (Type II diabetic rats with } \\
\text { NAFLD received irisin) } \\
\mathbf{1 8 7} \pm \mathbf{2 0}^{\text {***********}}\end{array}$} \\
\hline Glucose (mg/dl) & \pm SD $\bar{X}$ & & & \\
\hline & (r) & $(-0.829 *)$ & $\left(-0.843^{* *}\right)$ & $\left(-0.857^{* *}\right)$ \\
\hline \multirow{2}{*}{ Insulin (?IU/ml) } & \pm SD $\bar{X}$ & $17.3 \pm 1.2$ & 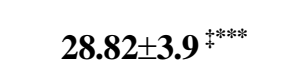 & $22.82 \pm 1.9^{\text {模******** }}$ \\
\hline & (r) & $\left(-0.765^{*}\right)$ & $\left(-0.837^{*}\right)$ & $\left(-0.827^{*}\right)$ \\
\hline \multirow{2}{*}{ HOMA-IR } & \pm SD $\bar{X}$ & $3.88 \pm 0.4$ & $19.4 \pm 2.1^{\text {**** }}$ & $10.5 \pm 0.5^{\ddagger * * * \beta^{* * * *}}$ \\
\hline & $(\mathbf{r})$ & $\left(-0.908^{* * *}\right)$ & $\left(-0.882^{* *}\right)$ & $\left(-0.862^{* *}\right)$ \\
\hline \multirow{2}{*}{ Cholesterol (mg/dl) } & $\pm \mathbf{S D} \bar{X}$ & $90.37 \pm 4.4$ & $141.75 \pm 3.9^{\text {部** }}$ & 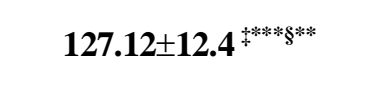 \\
\hline & (r) & $\left(-0.830^{*}\right)$ & $\left(-0.743^{*}\right)$ & $\left(-0.728^{*}\right)$ \\
\hline \multirow[t]{2}{*}{ Triglycerides (mg/dl) } & \pm SD $\bar{X}$ & $52.25 \pm 4.8$ & $100.75 \pm 12.4^{* * * *}$ & $88.37 \pm 6.4^{* * * * \beta^{* * *}}$ \\
\hline & $(\mathbf{r})$ & $\left(-0.831^{*}\right)$ & $\left(-0.849^{* *}\right)$ & $\left(-0.845^{* *}\right)$ \\
\hline \multirow{2}{*}{ HDL (mg/dl) } & $\pm \mathbf{S D} \overline{\mathrm{X}}$ & $40.62 \pm 1.5$ & 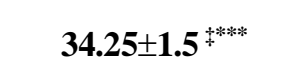 & $37.37 \pm 1.7^{\text {******* }}$ \\
\hline & $(\mathbf{r})$ & $\left(-0.930^{* *}\right)$ & $\left(-0.898^{* * *}\right)$ & $\left(-0.751^{*}\right)$ \\
\hline \multirow{2}{*}{ LDL (mg/dl) } & \pm SD $\bar{X}$ & $30.64 \pm 4.6$ & $75.04 \pm 7.3^{+* * *}$ & $63.55 \pm 6.2 *$ \\
\hline & $(\mathbf{r})$ & $\left(-0.885^{* *}\right)$ & $\left(-0.902^{* *}\right)$ & $\left(-0.762^{*}\right)$ \\
\hline Irisin (ng/ml) & \pm SD $\bar{X}$ & $7.50 \pm 1.2$ & $4.55 \pm 0.3^{* * * *}$ & $7.82 \pm 0.8^{8 * * * *}$ \\
\hline \multirow{2}{*}{ Albumin (g/dl) } & \pm SD $\bar{X}$ & $3.92 \pm 0.26$ & 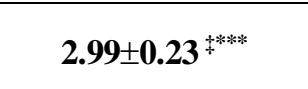 & $3.53 \pm 0.12 * * \% * * * *$ \\
\hline & $(\mathbf{r})$ & $\left(-0.844^{* *}\right)$ & $\left(-0.768^{*}\right)$ & $\left(-0.742^{*}\right)$ \\
\hline \multirow{2}{*}{$\operatorname{ALT}(\mathbf{U} / \mathbf{L})$} & \pm SD $\bar{X}$ & $39.97 \pm 6$ & 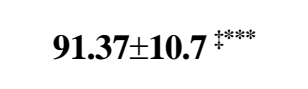 & $55.51 \pm 8.2^{* * * \& * * *}$ \\
\hline & (r) & $\left(-0.923^{* *}\right)$ & $\left(-0.780^{*}\right)$ & $\left(-0.739^{*}\right)$ \\
\hline \multirow[t]{2}{*}{$\operatorname{AST}(\mathbf{U} / \mathbf{L})$} & \pm SD $\bar{X}$ & $78.87 \pm 5.3$ & $128.62 \pm 11.9^{* * * *}$ & $93.87 \pm 9.5^{* * * \&^{* * * *}}$ \\
\hline & $(\mathbf{r})$ & $\left(-0.855^{* *}\right)$ & $(-0.938 * *)$ & $\left(-0.869^{* * *}\right)$ \\
\hline \multirow[t]{2}{*}{ TNF- $\alpha(\mathrm{pg} / \mathrm{ml})$} & \pm SD $\bar{X}$ & $13.97 \pm 1.3$ & $45.55 \pm 6.9^{\text {㲔*** }}$ & $35.75 \pm 5.2^{* * * * \varsigma^{* * *}}$ \\
\hline & (r) & $\left(-0.870^{* *}\right)$ & $\left(-0.864^{* * *}\right)$ & $\left(-0.865^{* *}\right)$ \\
\hline \multirow{2}{*}{ CRP (mg/l) } & \pm SD $\bar{X}$ & $0.036 \pm 0.008$ & 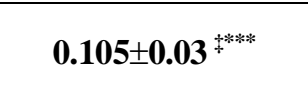 & 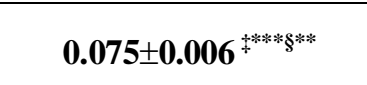 \\
\hline & $(\mathbf{r})$ & $\left(-0.899^{* * *}\right)$ & $\left(-0.866^{* * *}\right)$ & $\left(-0.813^{*}\right)$ \\
\hline
\end{tabular}

$\$=$ vs group I; $\S=$ vs group II; $r=$ correlation coefficient versus irisin level; $*=$ significant $(P<0.05)$;

$* *=$ significant $(\mathbf{P}<0.01) ; * * *=$ significant $(\mathbf{P}<\mathbf{0 . 0 0 1})$. 
Table (3): Oxidative stress markers in liver homogenate in all studied groups

\begin{tabular}{|c|c|c|c|c|}
\hline \multicolumn{2}{|l|}{ Parameters } & $\begin{array}{l}\text { Group I } \\
\text { (control) }\end{array}$ & $\begin{array}{c}\text { Group II } \\
\text { (Type II diabetic } \\
\text { rats with NAFLD) }\end{array}$ & $\begin{array}{c}\text { Group III } \\
\text { (Type II diabetic rats } \\
\text { with NAFLD received } \\
\text { irisin) }\end{array}$ \\
\hline \multirow{2}{*}{$\begin{array}{l}\text { MDA (nmol/g } \\
\text { protein) }\end{array}$} & \pm SD $\bar{X}$ & $1.59 \pm 0.2$ & $3.49 \pm 0.7^{* * * * *}$ & $2.17 \pm 0.2^{\ddagger * * \beta^{* * * *}}$ \\
\hline & $(\mathbf{r})$ & $\left(-0.829^{*}\right)$ & $\left(-0.833^{*}\right)$ & $\left(-0.765^{*}\right)$ \\
\hline \multirow{2}{*}{ SOD (U/mg protein) } & \pm SD $\bar{X}$ & $27.46 \pm 4.3$ & $15.89 \pm 1.066^{\ddagger * * *}$ & $22.9 \pm 5.5^{\ddagger * * \S^{* * * *}}$ \\
\hline & (r) & $\left(+0.763^{*}\right)$ & $\left(+0.804^{*}\right)$ & $\left(+0.732^{*}\right)$ \\
\hline \multirow{2}{*}{ GST (U/mg protein) } & \pm SD $\bar{X}$ & $2.39 \pm 0.2$ & 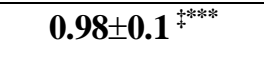 & $2.12 \pm 0.1 * * * * * * *$ \\
\hline & (r) & $\left(+0.750^{*}\right)$ & $\left(+0.781^{*}\right)$ & $\left(+0.742^{*}\right)$ \\
\hline
\end{tabular}

$\$=$ vs group I; $\S=$ vs group II; $r=$ correlation coefficient versus irisin level; $*$ significant $(P<0.05)$; $* *=$ significant $(\mathbf{P}<\mathbf{0 . 0 1}) ; * * *=$ significant $(\mathbf{P}<\mathbf{0 . 0 0 1})$.

Hepatic histopathological examination revealed normal liver tissue with normal architecture, normal hepatocyte and normal central vein in group $\mathbf{I}$ (control) [Fig 1 A] and HFD induced non- alcoholic steatohepatitis with marked micro and macrosteatosis in hepatocytes with ballooning degeneration and lobular inflammatory infiltrate with congested central vein in group II (Type II diabetic rats with NAFLD) [Fig 11 B]. Furthermore, group III (Type II diabetic rats with NAFLD received irisin), showed significant improvement in the degree of the hepatic lesions with mild fatty change in form of small intracytoplasmic vacuoles and apoptotic bodies in comparison to group II [Fig $1 \mathrm{C}$ ].
There was a significant decrease in hepatic injury score in group III in comparison to group II $(\mathrm{p}<0.001)$ with a significant negative correlation between irisin level and hepatic injury score in group II and group III $(\mathrm{p}<0.01$ and $\mathrm{p}<0.05$ respectively) [Table 4].

Hepatic immunohistochemical images stained with anti- cacspase 3 antibody showed significant increase in caspase 3 expression in group II in comparison to group I $(p<0.001)$ which showed faint positive staining for acspase 3 . However, in group III there was significant decrease in caspase 3 expression when compared to group II $(\mathrm{p}<0.001)$ [Table 5, Fig 2 A, B, C].

Table (4): Histopathological scoring of liver injury induced by HFD

\begin{tabular}{|l|c|c|c|c|}
\hline \multicolumn{2}{|c|}{ Groups } & $\begin{array}{c}\text { Group I } \\
\text { Parameters }\end{array}$ & $\begin{array}{c}\text { Group II } \\
\text { (Type II diabetic } \\
\text { rats with NAFLD) }\end{array}$ & $\begin{array}{c}\text { Group III } \\
\text { (Type II diabetic rats with } \\
\text { NAFLD received irisin) }\end{array}$ \\
\hline \multirow{2}{*}{ Hepatic injury score } & $\overline{\mathrm{X}} \pm$ SD & $\mathbf{0}$ & $\mathbf{6 . 1 2}^{*} \mathbf{0 . 8}^{* * * *}$ & $\mathbf{2 . 8 7 \pm \mathbf { 0 . 8 }}$ \\
\cline { 2 - 5 } & $\mathbf{r}$ & & $\mathbf{- 0 . 8 8 5}^{* * * * * * * * * *}$ & $\mathbf{0 . 7 1 4}^{* *}$ \\
\hline
\end{tabular}

$+=$ vs group I; $§=$ vs group II; $\mathbf{r}=$ correlation coefficient versus irisin level; $*=$ significant $(\mathbf{P}<0.05) ; * *=$ significant $(\mathbf{P}<0.01) ; * * *=$ significant $(\mathbf{P}<0.001)$. 
Table (5): Immunohistochemical expression of caspase 3 in the three studied groups

\begin{tabular}{|l|c|c|c|c|}
\hline Parameters & Groups & $\begin{array}{c}\text { Group I } \\
\text { (control) }\end{array}$ & $\begin{array}{c}\text { Group II } \\
\text { (Type II diabetic rats } \\
\text { with NAFLD) }\end{array}$ & $\begin{array}{c}\text { Group III } \\
\text { (Type II diabetic rats with } \\
\text { NAFLD received irisin) }\end{array}$ \\
\hline caspase 3 expression & $\overline{\mathrm{X}} \pm$ SD & $\mathbf{0 . 7 5} \pm \mathbf{0 . 5}$ & $\mathbf{2 . 8 7} \pm \mathbf{0 . 3}$ & $\mathbf{1 . 6 2}^{* * \mathbf{0 . 7}^{* * * *}}$ \\
\hline
\end{tabular}

\$= vs group I; $\S=$ vs group II; $*=$ significant $(P<0.05) ; * *=$ significant $(P<0.01) ; * * *=$ significant (P<0.001).

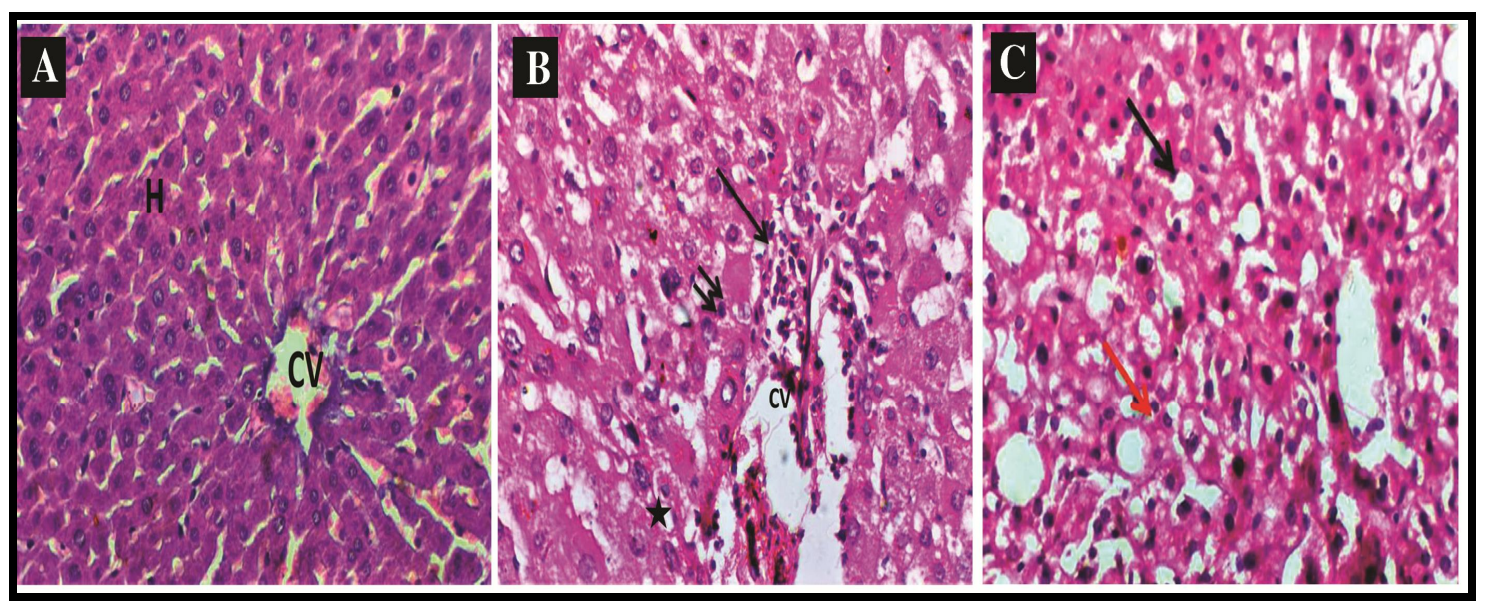

Figure (1): Liver tissue of rat showing: A) group I: central vein (CV) surrounded with normal hepatocytes arranged in cords $(\mathrm{H}), \mathbf{B})$ group II: NASH with marked micro and macrosteatosis in hepatocytes (star) with ballooning degeneration (double arrow) and Lobular inflammatory infiltrate (arrow) with congested central vein $(\mathrm{CV}), \mathbf{C})$ group III: Cells show mild fatty change in form of small intracytoplasmic vacuoles (black arrow) and apoptotic bodies (red arrow) (H\&E X400).

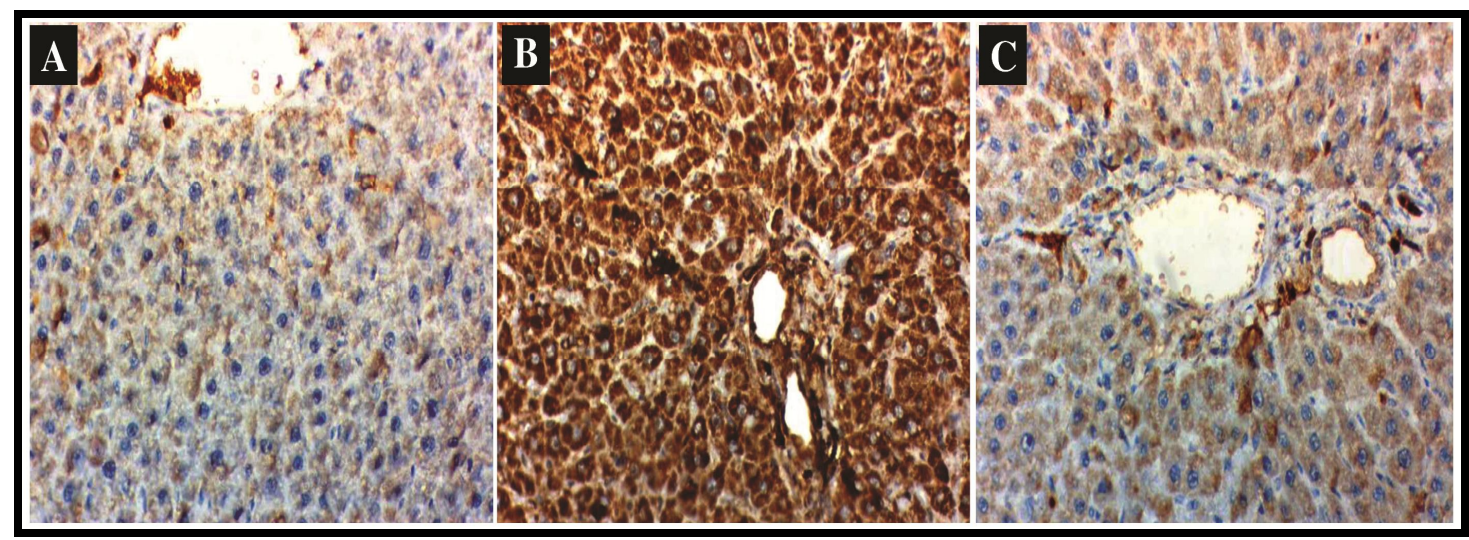

Figure (2): Liver tissue of rat stained with caspase 3 showing: A) group I: weak (1+) caspase 3 expression in normal hepatocytes, B) group II: strong (3+) caspase 3 expression, C) group III: moderate (2+) caspase 3 expression (IHC X400). 


\section{DISCUSSION}

In the current study, insulin resistance was induced via a HFD (Jiang et al., 2013), followed by a single STZ injection $(35 \mathrm{mg} / \mathrm{kg})$ to induce clear hyperglycemia. After 12 weeks of feeding, the rats were assessed to confirm NAFLD model establishment in the HFD fed- group (Fan, 2007). HFD/STZinduced NAFLD in type 2 diabetic rats is characterized by typical hepatocellular injury associated with disturbed lipid, and glucose metabolism and subsequent liver steatosis. Extended HFD intake induced a significant increase in body weight, BMI, $\mathrm{AC}$, fasting serum glucose and insulin levels, resulting in a higher HOMA IR compared with the control group. Furthermore, a HFD induced insulin resistance and disturbed glucose metabolism. Insulin resistance and dysregulation of fat metabolism are central players in the development of T2DM and NAFLD (Xu et al., 2015). Insulin resistance may initiate liver injury resulting in steatosis worsened by a HFD (Bell et al., 2012; Liu et al., 2014; Xu et al., 2014 and Ideta et al., 2015). Therefore, improving insulin sensitivity ameliorates T2DM and NAFLD. Additionally, a long-lasting HFD worsened the lipid profile as follows: elevated serum TG, TC, and LDL-c levels and decreased HDL-c levels. Moreover, a long-term HFD resulted in liver dysfunction as indicated by increased serum liver enzymes (ALT and AST), liver weight, and decreased serum albumin. Moreover, in this study, histopathological examination of the livers of diabetic rats revealed liver injury in the form of NASH establishment indicated by fatty infiltration and foci of inflammatory infiltration represented by spotty necrosis, and ballooning degeneration. Indeed, the histopathological findings revealed that this model faithfully imitated NAFLDassociated changes. These findings were in accordance with those of other previous studies (Shirakawa et al., 2011; Zhang \& Lu, 2015; Chien et al., 2016; El-Sherbiny et al., 2018 and Ibrahim \& Fathy, 2018).

Furthermore, this model showed increased serum TNF- $\alpha$ protein and CRP levels, indicating a worsening of the inflammatory burden associated with the NAFLD group.

In this study, oxidative stress biomarkers (MDA) and antioxidant enzymes (GST and SOD) were assessed in rat liver. The current work showed that the antioxidant activities of hepatic SOD and GST significantly decreased and that lipid peroxidation, which contributes to MDA levels, significantly increased in type 2 diabetic rats as reported by Zhu et al. (2016). The increased lipid peroxidation and decreased GST and SOD activities may be due to increased ROS generation (Diab and Hamza, 2016).

Our results also revealed that serum irisin levels significantly decreased due to type 2 diabetes mellitus in the NAFLD group compared with the control group. In addition, irisin levels were negatively correlated with BMI, AC, serum glucose, insulin, HOMA-IR index, TG, TC, LDLc, albumin, ALT, AST, TNF- $\alpha$, CRP and hepatic MDA levels in the type 2 diabetic group. However, there was significant positive correlation observed with hepatic SOD and hepatic GST.

These findings were supported by previous studies showing that serum irisin levels were gradually reduced with 
increased NAFLD severity (Zhang et al., 2013 and Polyzos et al., 2014). However, in contrast to our findings, serum irisin levels were found to be higher in the NAFLD group than in controls (Choi et al., 2014). Hyperinsulinemia, insulin resistance, hyperglycemia and high intrahepatic triglyceride content may result in reduced serum irisin levels. These findings are supported by other studies (Zhang et al., 2013; Al-Daghri et al., 2014; Kuzmicki et al., 2014; Yan et al., 2014 and Zhang et al., 2014b), indicating that irisin may act as a protective agent against NAFLD.

The effect of irisin administration on NAFLD in the HFD/STZ-induced type 2 diabetic rat model was examined in this study. Irisin produced a significant decreases in BMI, AC, FBG ( fasting blood glucose) levels, HOMA-IR, TG, $\mathrm{TC}$, and LDL-c and increase in HDL-c, in type 2 diabetic rats, indicating improvement of glycemia, lipid control and insulin sensitivity. These findings provided a basis for irisin to be used as a potential promising agent for the management of insulin resistance, hyperlipidemia, and type $2 \mathrm{DM}$.

Skeletal muscles act as an endocrine organ, secreting myokines that mediate the beneficial effects of exercise (Pedersen and Febbraio, 2012). In this situation, irisin, as a myokine, may encourage browning of white adipose tissue, resulting in increased energy expenditure by up regulating the genes associated with browning, such as uncoupling protein 1 (UCP-1) and peroxisome proliferative activated receptor- $\gamma$ (PPAR- $\gamma$ ) (Bostr?m et al., 2012 and Zhang et al., 2016). This process may be mediated by phosphorylation of p38 mitogen-activated protein kinase and extracellular signal-related kinase (Zhang et al., 2014a). Moreover, lipolysis-related genes are up regulated by irisin, increasing the release of glycerol and decreasing lipid deposition in fat cells (Gao et al., 2016). Furthermore, irisin increases insulin-mediated glucose uptake by elevating GLUT-4 expression in fat cells (Huh et al., 2014). These remarkable properties of irisin make this adipomyokine a potential therapeutic candidate for obesity and other metabolic disorders.

Irisin may prevent liver triglycerides deposition by stimulating the PPARa signaling pathway involved in lipid metabolism controlling fat oxidation (Hondares et al., 2011). In addition, irisin inhibits cholesterol transport and elevates HDL levels (Xu et al., 2009 and Badimon and Vilahur, 2012). Therefore, irisin could play an important role in the prevention of hepatic steatosis.

Regarding the effect of irisin on liver function, its administration resulted in decreased liver weight, serum liver enzymes (ALT and AST) levels, and increased serum albumin level, indicating improvement in liver dysfunction induced by HFD/STZ in NAFLD rat models.

In accordance, the hepatic histopathological examination in the NAFLD group treated with irisin showed amelioration of the degree of fatty infiltration, foci of inflammatory infiltration and ballooning degeneration. Indeed, the current results demonstrated that irisin may prevent the progression of NAFLD in type 2 diabetic rats by 
modulating lipid metabolism and dyslipidemia.

The current results indicated that irisin lessened the inflammatory burden in rats with NAFLD and decreased serum TNF- $\alpha$ protein and CRP levels, suggesting a potential anti-inflammatory role of irisin. The present findings were consistent with those of other studies that reported a potential anti-inflammatory effect of irisin (Choi et al., 2014; Polyzos et al., 2014 and Park et al., 2015). In agreement, irisin treatment reduces the inflammatory markers associated with palmitic acidinduced lipogenesis. This decrease may be mediated by inhibition of protein arginine methyl transferase 3 (PRMT3), which is involved in liver lipogenesis (Park et al., 2015). Moreover, irisin may induce phenotypic switching of macrophages from the pro-inflammatory (M1) to antiinflammatory (M2) state in adipose tissue (Dong et al., 2016). Therefore, serum irisin levels are significantly elevated in the early stages of NAFLD, probably as a defense mechanism, and are reduced with disease progression (Choi et al., 2014).

In addition, the current study demonstrated an antioxidant effect of irisin in rats with NAFLD, as irisin treatment reduced lipid peroxidation contributing to hepatic MDA levels and increased hepatic SOD and GST. Accumulating evidence highlights the antioxidant effect of irisin, as Park et al. (2015) showed that irisin diminished FFA-induced oxidative stress via Protein arginine N-methyltransferase 3 (PRMT3) regulation confirmed by inhibiting the expression of inflammatory markers. PRMT1 and PRMT3 share the pathophysiology of hepatic lipogenesis.
Thus, PRMT isoforms could be therapeutic targets. In accordance, the antioxidant activity of irisin has been demonstrated by other studies ( $L u$ et al., 2015; Zhu et al., 2015 and Liu et al., 2017). Therefore, irisin may be a promising agent for the management of diabetic vascular complications ( $L u$ et al., 2015). Additionally, it decreases the oxidative stress induced by high sugar and high fat in human umbilical vein endothelial cells by impeding the activation of PKC-/NADPH oxidase and NF-B/iNOS signaling pathways (Liu et al., 2017).

Moreover, immunohistochemical findings in our study showed strong caspase 3 expression in rats with NALFD which is in agreement with El-Sherbiny et al. (2018). However, after irisin treatment a marked decrease in caspase-3 expression was found, which is in line with Song et al. (2014) who reported that irisin may have anti-apoptotic effects via a reduction in the expression of many apoptotic markers induced by hyperglycemia, such as Caspase-3.

Consistent with these findings, $B i$ et al. (2019) demonstrated that exogenous irisin alleviates liver ischemia-reperfusion (I/R) injury. Irisin improved liver function, reduced liver necrosis and cell apoptosis, and relieved the inflammatory response after hepatic I/R. Moreover, it inhibited mitochondrial fission- related proteindynamin related protein 1 (drp-1) and fission 1 (Fis-1) expression in hepatic I/R. Additionally, irisin increased mitochondrial content and increased expression of mitochondrial biogenesisrelated PPAR $\gamma$ co-activator $1 \alpha$ (PGC- $1 \alpha)$ and mitochondrial transcription factor 
(TFAM). Furthermore, irisin decreased oxidative stress by up regulating uncoupling protein 2 (UCP-2) expression in hepatic $\mathrm{I} / \mathrm{R}$. These results reveal that treatment with exogenous irisin alleviated hepatic I/R injury by restraining mitochondrial fission, promoting mitochondrial biogenesis and relieving oxidative stress. Irisin treatment also appears to be a promising therapeutic approach for hepatic I/R injury.

Conclusion: Taken together, these data implied that irisin may be used as a therapeutic agent against the progression of NAFLD in type 2 diabetic rats through its role in glucolipid metabolism and its anti-inflammatory and antioxidant effects confirmed by partial amelioration of hepatic functions and morphology. Furthermore, although of the administration of exogenous irisin achieved beneficial effects on NAFLD in type 2 diabetic rats, the present findings were based only on basic research, and clinical studies are necessary in the future.

Future studies should evaluate the impact of irisin on the hepatic mRNA levels of nuclear factor, erythroid 2-like 2 (Nrf2).

Some of the discrepancies found between the current results and other studies may be due to variations in the animal models, drug doses, and treatment durations.

\section{ACKNOWLEDGEMENT}

The authors acknowledge Dr. Mona Mostafa Ahmed, Lecturer of Pathology, Faculty of Medicine, Zagazig University, for performing the histopathologic and immunohistochemical studies.

\section{REFERENCES}

1. Ahrén B and Scheurink AJ (1998): Marked hyperleptinaemia after high fat diet associated with severe glucose intolerance in mice. Eur J Endocrinal., 139: 461-467. PMID: 9820626

2. Al-Daghri NM, Alkharfy KM, Rahman S, Vinodson B, Sabico S, Piya MK, Harte AL, McTernan PG, Alokail MS and Chrousos GP (2014): Irisin as a predictor of glucose metabolism in children: Sexually dimorphic effects. Eur. J. Clin. Invest., 44 (2): 119-124.

3. Altunkaynak $\mathbf{Z}$ (2005): Effects of high fat diet induced obesity on female rat livers (A histochemical study). Eur. J. Gen. Med., 2(3):100-109.

4. Arias-Loste MT, Ranchal I, RomeroG?mez $M$ and Crespo J (2014): Irisin, a Link among Fatty Liver Disease, Physical Inactivity and Insulin Resistance. Review. Int. J. Mol. Sci., 15: 23163-23178;

5. Aydin S, Kuloglu T, Aydin S, Kalayci M, Yilmaz M, Cakmak T, Albayrak S, Gungor S, Colakoglu N and Ozercan IH (2014): A comprehensive immunohistochemical examination of the distribution of the fat-burning protein irisin in biological tissues. Peptides., 61:130-136.

6. Badimon L and Vilahur G (2012): LDLcholesterol versus HDL-cholesterol in the atherosclerotic plaque: Inflammatory resolution versus thrombotic chaos. Ann. N. Y. Acad. Sci., 1254:18-32.

7. Bell LN, Wang J, Muralidharan $S$, Chalasani S, Fullenkamp AM, Wilson LA, Sanyal AJ, Kowdley KV, NeuschwanderTetri BA, Brunt EM, McCullough AJ, Bass NM, Diehl AM, Unalp-Arida $A$ and Chalasani N (2012): Relationship between adipose tissue insulin resistance and liver histology in nonalcoholic steatohepatitis: A pioglitazone versus vitamin $\mathrm{E}$ versus placebo for the treatment of nondiabetic patients with nonalcoholic steatohepatitis trial follow up study. Hepatology., 56 (4): 1311-1318.

8. Bi J, Zhang J, Ren Y, Du Z, Li Q, Wang Y, Wei S, Yang L., Zhang J, Liu C, Lv Y and Wu R (2019): Irisin alleviates liver ischemiareperfusion injury by inhibiting excessive mitochondrial fission, promoting 
mitochondrial biogenesis and decreasing oxidative stress. Redox Biology., 20:296-306.

9. Bonora E, Targher G, Alberiche M, Bonadonna RC, Saggiani F, Zenere MB, Monauni $T$ and Muggeo $M$ (2000): Homeostasis model assessment closely mirrors the glucose clamp technique in the assessment of insulin sensitivity: studies in subjects with various degrees of glucose tolerance and insulin sensitivity. Diabetes Care., 23(1): 57-63.

10. Bostr?m P, Wu J, Jedrychowski MP, Korde A, Ye L, Lo JC, Rasbach KA, Bostr?m EA, Choi JH, Long JZ, Kajimura S, Zingaretti MC, Vind BF, Tu H, Cinti S, H?jlund K, Gygi SP and Spiegelman BM (2012): A pgc1-alphadependent myokine that drives brown-fat-like development of white fat and thermogenesis. Nature., 481: 463-468.

11. Buzzetti E, Pinzani $M$ and Tsochatzis EA (2016): The multiple-hit pathogenesis of nonalcoholic fatty liver disease (NAFLD). Metabolism., 65: 1038-1048.

12. Chen N, Li Q, Liu J and Jia S (2016): Irisin, an exercise-induced myokine as a metabolic regulator: an updated narrative review. Diabetes Metab. Res. Rev. 32 (1):5159.

13. Chien MY, Ku YH, Chang JM, Yang CM and Chen CH (2016): Effects of herbal mixture extracts on obesity in rats fed a highfat diet. J. Food Drug Anal., 24(3):594-601.

14. Choi ES, Kim MK, Song MK, Kim JM, Kim ES, Chung WJ, Park KS, Cho KB, Hwang JS and Jang BK (2014): Association between Serum Irisin Levels and Non-Alcoholic Fatty Liver Disease in Health Screen Examinees. PLoS One, 9 (10): e110680.

15. Del Ben M, Polimeni L, Baratta F, Pastori D, Loffredo $L$ and Angelico $F$ (2014): Modern approach to the clinical management of non alcoholic fatty liver disease. World J Gastroenterol., 20: 83418350.

16. Diab AEA and Hamza RZ (2016): Monosodium glutamate induced hepatotoxicity and the possible mitigating effect of vitamin C and propolis. J. Advances in Medical and Pharmaceutical Sciences, 7 (4): $1-10$

17. Dong J, Dong Y, Dong Y, Chen F, Mitch WE and Zhang $L$ (2016): Inhibition of myostatin in mice improves insulin sensitivity via irisin-mediated cross talk between muscle and adipose tissues. Int. J. Obes., 40(3):434-442.

18. Dozic B, Glumac S, Boricic N, Dozic M, Anicic $B$ and Boricic, I (2016): Immunohistochemical expression of caspases 9 and 3 in adenoid cystic carcinoma of salivary glands and association with clinicopathological parameters. J BUON., 21(1):152-160.

19. El-Sherbiny, M., Eldosoky, M., El-Shafey, M., Othman, G., Elkattawy, H.A., Bedir, T., and Elsherbiny N.M. (2018): Vitamin D nanoemulsion enhances hepatoprotective effect of conventional vitamin $\mathrm{D}$ in rats fed with a high-fat diet. Chem Biol Interact., 288:65-75.

20. Fan JG (2007): An introduction of strategies for the management of nonalcoholic fatty liver disease (NAFLD) recommended by asia pacific working party on NAFLD. Zhonghua Gan Zang Bing Za Zhi 15: 552 553, PMID: 17669255. (In Chinese).

21. Fernando B, Marley R, Holt S, Anand R, Harry D, Sanderson P, Smith R, Hamilton $G$ and Moore $K$ (1998): N-acetylcysteine prevents development of the hyper dynamic circulation in the portal hypertensive rat. Hepatology, 28 (3): 689-694.

22. Fossati P and Prencipe L (1982): Serum triglycerides determined calorimetrically with an enzyme that produces hydrogen peroxide. Clin Chem., 28(10): 2077-2080. PMID: 6812986

23. Friedewald WT, Levy RI, and Fredrickson DS (1972): Estimation of the concentration of low-density lipoprotein cholesterol in plasma, without use of the preparative ultracentrifuge. Clin Chem., 18 (6):499-502. PMID: 4337382 
24. Fruci B, Giuliano S, Mazza A, Malaguarnera $R$ and Belfiore $A$ (2013): Nonalcoholic Fatty liver: A possible new target for type 2 diabetes prevention and treatment. Int J Mol Sci., 14: 22933-22966.

25. Gao S, Li F, Li H, Huang Y, Liu Y, and Chen Y (2016): Effects and Molecular Mechanism of GST-Irisin on Lipolysis and Autocrine Function in 3T3-L1 Adipocytes. PLoSOne., 11(1):e0147480.

26. Gerbaix M, Metz L, Ringot E. and Courteix D (2010): Visceral fat mass determination in rodent: validation of dualenergy X-ray absorptiometry and anthropometric techniques in fat and lean rats. Lipids Health Dis., 9; 9:140.

27. Hassan K, Bhalla V, El Regal ME and A Kader HH (2014): Nonalcoholic fatty liver disease: A comprehensive review of a growing epidemic. World J Gastroenterol., 20:12082-12101.

28. Higuera de la Tijera $F$ and Serv? Caama?o AI (2015): Pathophysiological mechanisms involved in non alcoholic steatohepatitis and novel potential therapeutic targets. World J Hepatol., 7:1297-1301.

29. Hondares E, Rosell M, Daz-Delfh J, Olmos Y, Monsalve $\mathbf{M}$, Iglesias R, Villarroya $F$ and Giralt $M$ (2011): Peroxisome proliferator-activated receptor alpha (PPAR alpha) induces PPAR gamma coactivator 1alpha (PGC-1alpha) gene expression and contributes to thermogenic active-tion of brown fat: Involve-ment of PRDM16. J. Biol. Chem., 16; 286(50):4311243122.

30. Hu SH, Jiang T, Yang SS, Yang Y (2013) Pioglitazone Ameliorates Intracerebral Insulin Resistance and Tau-protein Hyperphosphorylation in Rats with Type 2 Diabetes. Exp. Clin. Endocrinol. Diabetes., 121(4): 220-224.

31. Huh JY, Dincer F, Mesfum $E$ and Mantzoros CS (2014): Irisin stimulates muscle growth-related genes and regulates adipocyte differentiation and metabolism in humans. Int. J. Obes., 38(12):1538-1544.
32. Ibrahim RH and Fathy MA (2018): Sexual Dimorphism in Serum Kisspeptin Level in Experimentally Induced Non Alcoholic Fatty Liver Disease in Adult Albino Rats. Am. J. Biomed. Sci., 10(2): 115-128;

33. Ideta T, Shirakami Y, Miyazaki T, Kochi T, Sakai H Moriwaki H, and Shimizu M (2015): The dipeptidyl peptidase 4 inhibitor teneligliptin attenuates hepatic lipogenesis via AMPK activation in nonalcoholic fatty liver disease model mice. Int $\mathrm{J}$ Mol Sci., 16(12):29207-29218.

34. Issa D, Patel V and Sanyal AJ (2018): Future therapy for non-alcoholic fatty liver disease. Liver Int., 38: 56-63.

35. Jiang X, Ma H, Wang Y and Liu Y (2013): Early life factors and type 2 diabetes mellitus. J Diabetes Res., 2013:485082.

36. Kimberly MM, Vesper HW, Caudill SP, Cooper GR, Rifai N, Dati F and Myers GL (2003): Standardization of immunoassay for measurement of high-sensitivity $\mathrm{C}$ reactive protein phase 1: Evaluation of secondary reference materials. Clin Chem., 49(4) 611616.

37. Kleiner, DE, Brunt EM, Van Natta M, Behling C, Contos MJ, Cummings OW, Ferrell LD, Liu YC, Torbenson MS, Unalp-Arida A, Yeh M, McCullough AJ and Sanyal AJ (2005): Design and validation of a histological scoring system for nonalcoholic fatty liver disease. Hepatology, 41(6):1313-1321.

38. Kuzmicki M, Telejko B, Lipinska D, Pliszka J, Szamatowicz M, Wilk, J, Zbucka-Kretowska M Laudanski, P, Kretowski A, Gorska M, and Szamatowicz J (2014): Serum irisin con-centration in women with gestational diabetes. Gynecol. Endocrinol., 30(9):636-639.

39. Leite NC, Villela Nogueira CA, Cardoso CR and Salles GF (2014): Non alcoholic fatty liver disease and diabetes: From physiopathological interplay to diagnosis and treatment. World J Gastroenterol., 20: 83778392.

40. Lemos ET, Nunes $S$, Teixeira $F$ and Reis $F$ (2011): Regular physical exercise training 
assists in preventing type 2 diabetes development: focus on its antioxidant and anti-inflammatory properties. Cardiovasc Diabetol., 10:12-26

41. Liu S, Du F, Li X, Wang M, Duan R, Zhang J, Wu Y and Zhang $Q$ (2017): Effects and underlying mechanisms of irisin on the proliferation and apoptosis of pancreatic beta cells. PLoS One, 12(4):e0175498.

42. Liu Y, Wei R, and Hong TP (2014): Potential roles of glucagon like peptide 1 based therapies in treating nonalcoholic fatty liver disease. World J Gastroenterol., 20 (27): 9090-9097.

43. L?ffler D, Müller U, Scheuermann K, Friebe D, Gesing J, Bielitz J, Erbs S, Landgraf K, Wagner IV, Kiess, $W$ and K?rner A (2015): Serum irisin levels are regulated by acute strenuous exercise. J. Clin. Endocrinol. Metab., 100: 1289-1299.

44. Lu J, Xiang G, Liu M, Mei W, Xiang, L and Dong $\mathbf{J}$ (2015): Irisin protects against endothelial injury and ameliorates atherosclero-sis in apolipoprotein e-null diabetic mice. Atherosclerosis, 243(2):438448.

45. Misra H, and Fridovich I (1972): The role of superoxide anion in the autooxidation of epinephrine and simple assay for superoxide dismutase. J. Biol. Chem., 247(10): 31703175 .

46. Nauck MA, Holst JJ and Willms B (1997): Glucagon-like peptide 1 and its potential in the treatment of non-insulin-dependent diabetes mellitus. Horm Metab Res., 29(9): 411- 416 .

47. Nishizawa H, Shimomura I, Kishida K, Maeda $N$ and Kuriyama $H$ (2002): Androgens decrease plasma adiponectin, an insulin-sensitizing adipocyte-derived protein. Diabetes., 51(9): 2734-2741.

48. Novelli E, Diniz Y, Galhardi C, Ebaid G, Rodrigues H, Mani F, Fernandes A, Cicogna A and Novelli J (2007): Anthropometrical parameters and markers of obesity in rats. Laboratory Animals, 41: 111-119.
49. Palacios-Gonz?lez B, Vadillo-Ortega F, Polo-Oteyza E, S?nchez T, Ancira-Moreno M Romero-Hidalgo S, Mer?z N, and Antuna-Puente B (2015): Irisin levels before and after physical activity among school-age children with different BMI: a direct relation with leptin. Obesity., 23:729-732.

50. Panati K, Suneetha $Y$ and Narala VR (2016): Irisin/FNDC5- -an updated review. Eur. Rev.Med. Pharmacol. Sci., 20: 689-697. PMID: 26957272.

51. Park MJ, Kim DI, Choi JH, Heo YR and Park SH (2015): New role of irisin in hepatocytes: The protective effective of hepatic steatosis in vitro. Cellular signaling., 27(9):1831-1839.

52. Pedersen BK and Febbraio MA (2012): Muscles, exercise and obesity: skeletal muscle as a secretory organ. Nat. Rev., $8(8): 457-465$.

53. Polyzos SA, Kountouras J, Anastasilakis AD, Geladari EV and Mantzoros CS (2014): Irisin in patients with nonalcoholic fatty liver disease. Metabolism, 63(2):207217.

54. Rajurkar RB, Khan LH and Gijar GT (2003): Studies on levels of glutathione $\mathrm{s}$ transferase, its isolation and purification from Helicoverpa amigera. Current Science, 85 (9): 1355 - 1360

55. Reaven GM (1991): Insulin resistance, hyperinsulinemia, hypertriglyceridemia and hypertension. Parallel between human disease. Diab. Care., 14(3):195-202.

56. Sanyal AJ, Brunt EM, Kleiner DE, Kowdley KV, Chalasani N, Lavine JE, Ratziu V, and McCullough A (2011): Endpoints and clinical trial design for nonalcoholic steatohepatitis. Hepatology., 54(1): 344-353.

57. Shirakawa J, Fujii H, Ohnuma K, Sato K, Ito Y, Kaji M, Sakamoto, E, Koganei M, Sasaki H, Nagashima Y, Amo K, Aoki K, Morimoto C, Takeda $\mathbf{E}$ and Terauchi $\mathbf{Y}$ (2011): Diet induced adipose tissue inflammation and liver steatosis are prevented by DPP 4 inhibition in diabetic mice. Diabetes, 60(4):1246-1257. 
58. So WY and Leung PS (2016): Irisin ameliorates hepatic glucose/lipid metabolism and enhances cell survival in insulin-resistant human HepG2 cells through adenosine monophosphate-activated protein kinase signaling. The International Journal of Biochemistry \& Cell Biology, 78:237-247.

59. Song H, Wu, F, Zhang Y, Zhang Y, Wang F, Jiang M, Wang Z, Zhang M, Li S, Yang L, Wang XL, Cui T and Tang D (2014): Irisin promotes human umbilical vein endothelial cell proliferation through the erk signaling pathway and partly suppresses high glucose-induced apoptosis. PLoS One, 9(10): e110273.

60. Stoskopf M (1993): Fish medicine. pbl: W.B. Saunders Company, Philadelphia, U.S.A., pp: 882

61. Tietz, N.W. (1995): Clinical Guide to Laboratory Tests, 3rd Ed., pbl: W.B. Saunders Company, Philadelphia, PP 509580 .

62. Varshney R and Kale RK (1990): Effects of calmodulin antagonists on radiation induced lipid peroxidation in microsomes. Int. J. Rad. Biol., 58(5):733-743.

63. Vassault A (1983): Lactate dehydrogenase. UV method with pyruvate and NADH. In: H. U. Bergmeyer, editor. ed. Methods of enzymatic analysis, 3: 118-126.

64. Virtanen KA (2014): Bat thermo -genesis: linking shivering to exercise. Cell Metab., 19: 352-354.

65. Xin C, Liu J, Zhang J, Zhu D, Wang H, Xiong L, Lee Y, Ye J, Lian K, Xu C, Zhang L, Wang $Q$, Liu $Y$ and Tao $L$ (2015): Irisin improves fatty acid oxidation and glucose utilization in type 2 diabetes by regulating the AMPK signaling pathway. International Journal of Obesity, 40(3): 443451 .

66. Xu J, Lloyd DJ, Hale C, Stanislaus S, Chen M, Sivits G, Vonderfecht S, Hecht R, Li YS, Lindberg RA, Chen JL, Jung DY, Zhang Z, Ko HJ, Kim JK and Véniant MM (2009): Fibroblast growth factor 21 reverses hepatic steatosis, increases energy expenditure, and improves insulin sensitivity in diet induced obese mice. Diabetes., 58(1):250-9.

67. Xu F, Li Z, Zheng X, Liu H, Liang H, Xu $H$, Chen $Z$, Zeng $K$ and Weng $J$ (2014): SIRT1 mediates the effect of GLP 1 receptor agonist exenatide on ameliorating hepatic steatosis. Diabetes, 63: 63(11):3637-3646.

68. Xu L, Kitade H, Ni Y and Ota T (2015): Roles of chemokines and chemokine receptors in obesity-associated insulin resistance and nonalcoholic fatty liver disease. Biomolecules, 5(3):1563-1579.

69. Yan B, Shi X, Zhang H, Pan L, Ma Z, Liu S Liu Y, Li X, Yang S, and Li Z (2014): Association of serum irisin with metabolic syndrome in obese Chinese adults. PLoS One., 9(4):e94235.

70. Yang RZ, Lee MJ, Hu H, Pray J, Wu HB, Hansen BC, Shuldiner AR, Fried SK, McLenithan JC and Gong DW (2006): Identification of omentin as a novel depotspecific adipokine in human adipose tissue: possible role in modulating insulin action. Am. J. Physiol. Endocrinol. Metab., 290 (6): 1253-1261.

71. Zhang M, Chen P, Chen S, Sun Q, Zeng QC, Chen JY, Liu YX, Cao XH, Ren M and Wang JK (2014 b): The association of new inflammatory markers with type 2 diabetes mellitus and macrovascular complications: A preliminary study. Eur. Rev. Med. Pharmacol. Sci., 18 (11): 15671572 ,

72. Zhang HJ, Zhang XF, Ma ZM, Pan LL, Chen Z, Han HW, Han CK, Zhuang XJ, Lu Y, Li XJ, Yang SY, and Li XY (2013): Irisin is inversely associated with intrahepatic triglyceride contents in obese adults. J. Hepatol., 59(3):557-562.

73. Zhang QQ and Lu LG (2015): Nonalcoholic fatty liver disease: dyslipidemia, risk for cardiovascular complications, and treatment strategy. J. Clin. Transl. Hepatol., 3(1):78-84.

74. Zhang Y, Li R, Meng Y, Li S, Donelan W, Zhao Y, Qi L, Zhang M, Wang X, Cui T, Yang LJ and Tang D (2014a): Irisin stimulates browning of white adipocytes through mitogen-activated protein kinase p38 
MAP kinase and ERK MAP kinase signaling. Diabetes., 63(2):514-525.

75. Zhang Y, Xie C, Wang H, Foss RM, Clare M, George EV, Li S, Katz A, Cheng H, Ding Y, Tang D, Reeves WH and Yang LJ (2016): Irisin exerts dual effects on browning and adipogenesis of human white adipocytes. Am. J. Physiol.-Endocrinol. Metab., 311: 530541.

76. Zhao CY, Jiang LL, Li L, Deng ZJ, Liang BL and Li JM (2004): Peroxisome proliferator activated receptor-gamma in pathogenesis of experimental fatty liver disease. World J. Gastroenterol., 10(9):13291332.
77. Zhu D, Wang H, Zhang J, Zhang X, Xin C, Zhang F, Lee $Y$, Zhang $L$, Lian $K$, Yan W, Ma X, Liu Y and Tao L (2015): Irisin improves endothelial function in type 2 diabetes through reducing oxidative/nitrative stresses. J. Mol. Cell. Cardiol., 87:138-147.

78. Zhu KX, Nie SP, Tan LH, Li, C., Gong DM and Xie MY (2016): Polysaccharide from Ganoderma atrum improves liver function in type 2 diabetic rats via antioxidant action and short-chain fatty acids excretion. J. Agric. Food Chem., 64(9):1938-1944. 


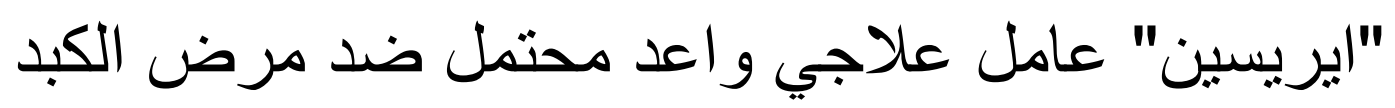

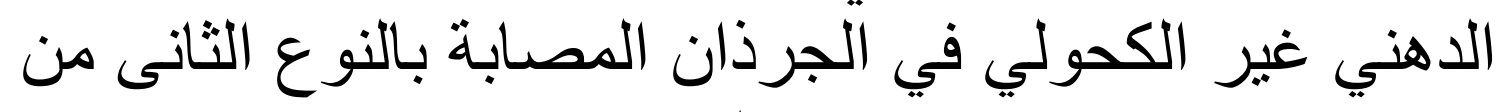
مرض السكري

هانى أحمد القطاوى (1) (2) (3) - وسام محمد رضا محمود عاثيور (1)

قسم الفسيولوجيا الطبيه ـ كلية الطب ـ جامعة الزقازيق ـ مصر (1)

وحدة علاج وأبحاث السمنة ـ كلية الطب - جامعة الزقازيق - مصر (2)

كلية الطب ـ جامعة المعرفة ـ السعودية (3)

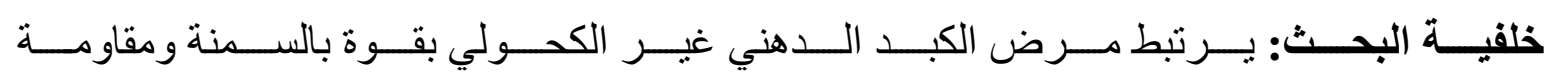
الإنسولين ومرض السكري من النوع الثاني.

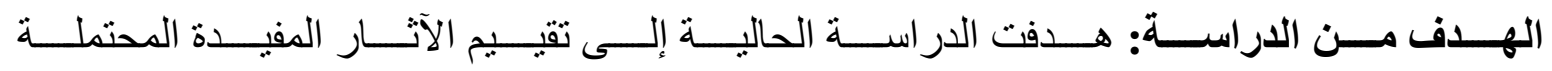

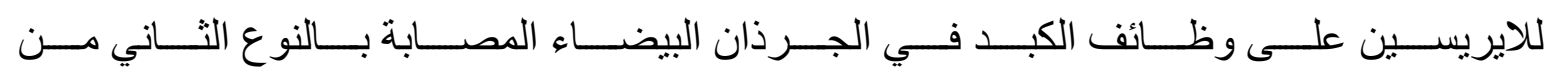
السكرى ومحاولة توضيح الآليات الأساسية.

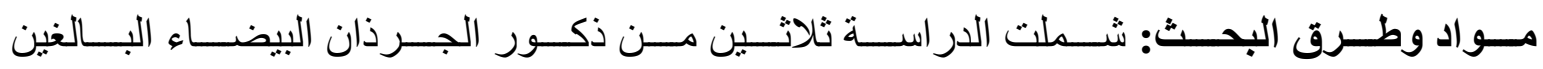

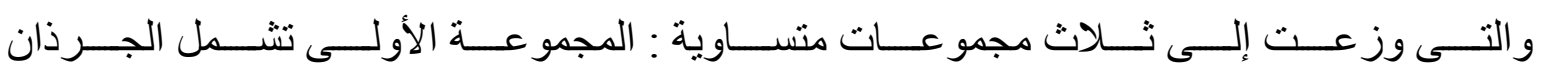

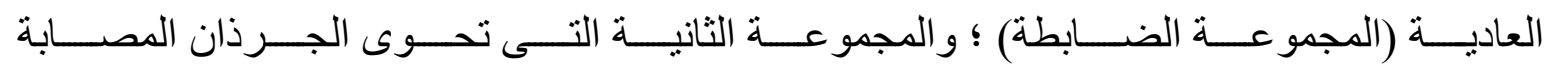

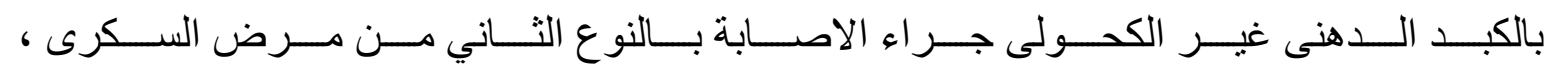

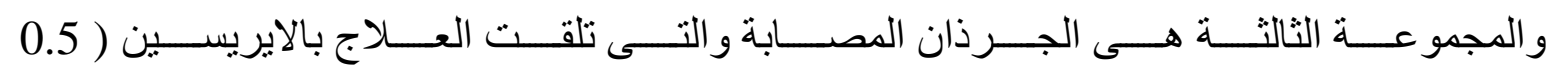
ميكروجر ام لكل جر ام من وزن الجسم يوميا لمدة 8 أسابيع)

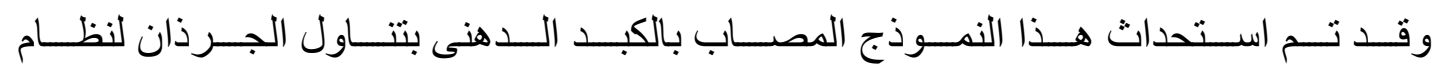

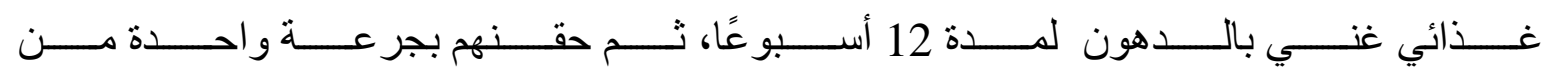
الستربتزوتوسين ( 35 ملجم لكل كجم من وزن الجسم) بل بهوب

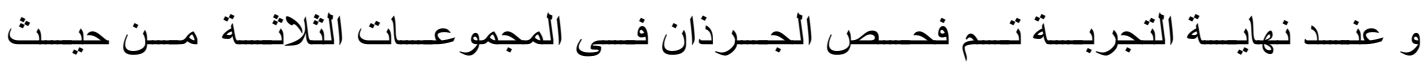

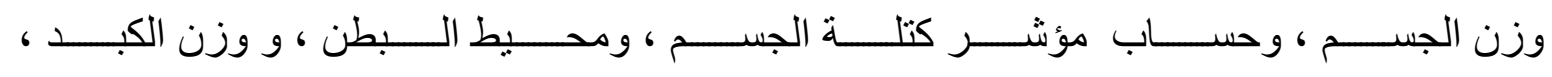

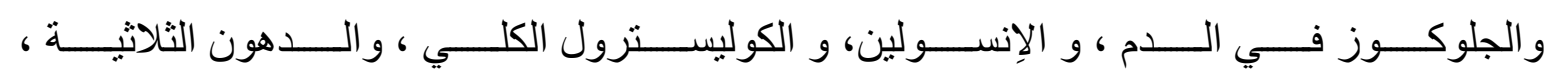

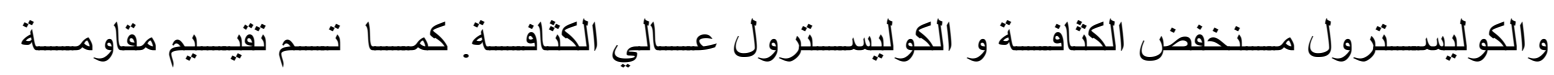




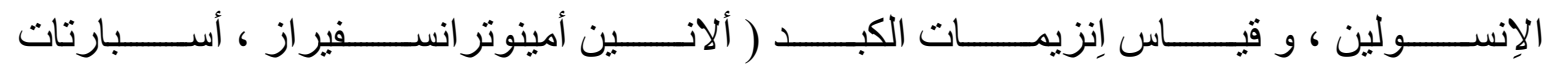

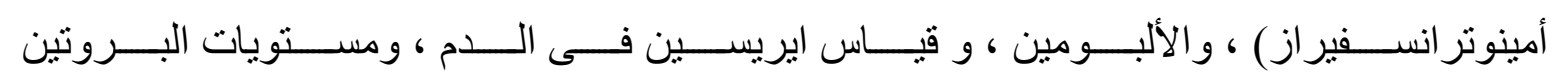

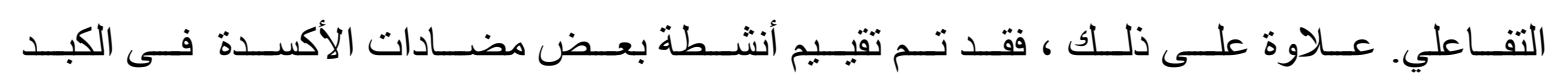

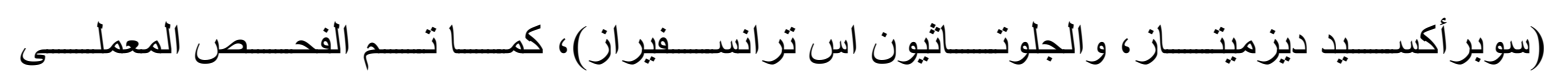
للأنسجة الكبدية.

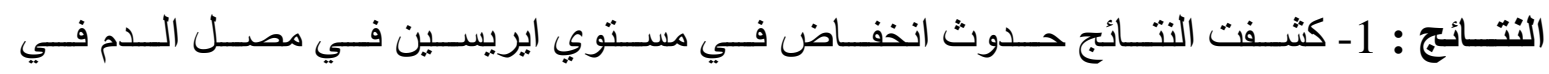

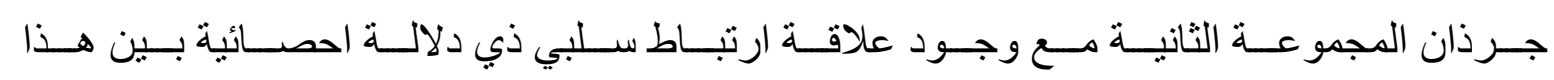

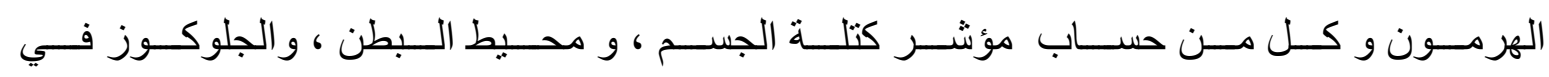

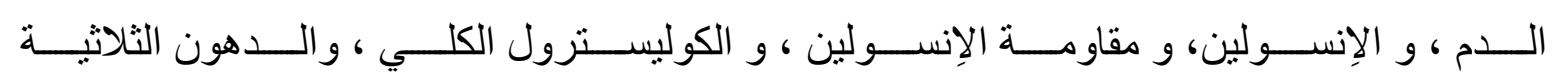

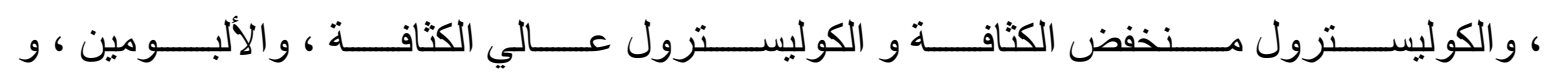

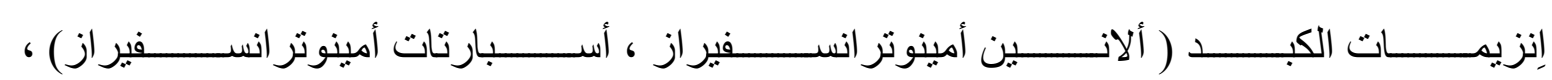
ومستويات البروتين التفاعلي.

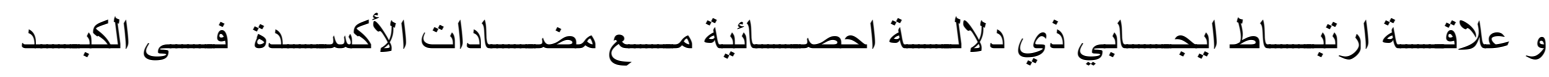

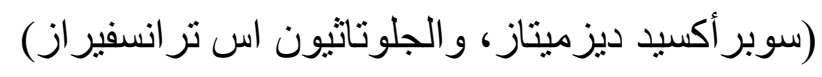

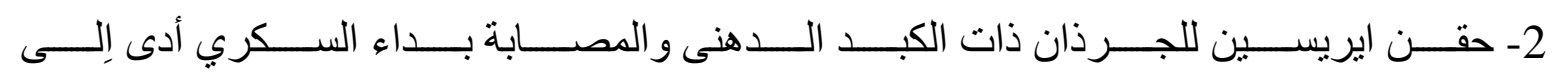

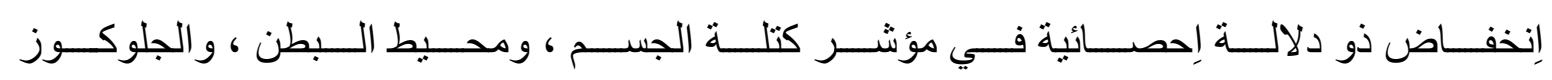

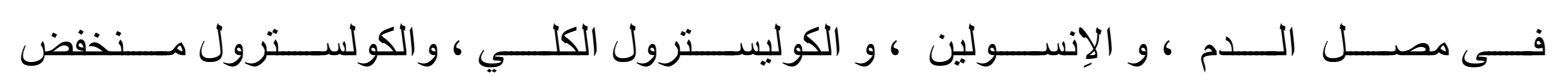

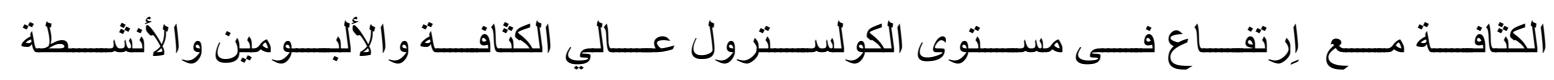

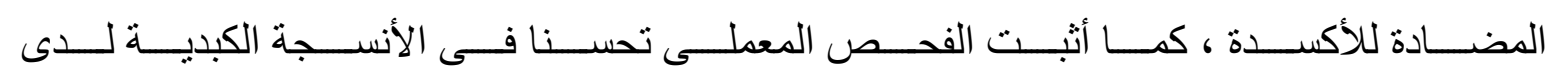
الجرذان المصابة بالكبد الدهنى. - ادك.

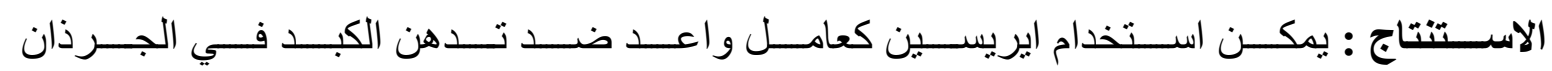

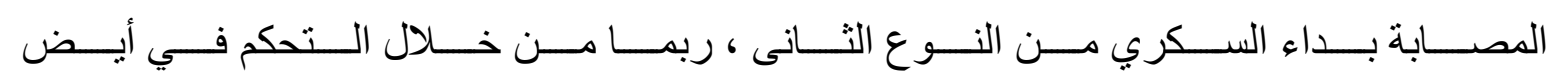
الجلوكوز و الدهون ، و عبر آثاره المفيدة المضادة للإلتهابات و المضادة للأكسدة. 